\title{
The effect of socio-cultural factors on the international flight safety research findings
}

\author{
Oleksandra Matyukhina ${ }^{1}$, Sergii Ordenov ${ }^{1}$, Tetiana Poda $^{1 *}$, and Nadiia Sukhova ${ }^{1}$ \\ ${ }^{1}$ National Aviation University, 1 Liubomyra Huzara ave., Kyiv, 03058, Ukraine
}

\begin{abstract}
Nowadays we can get anywhere in the world. The success of civil aviation became possible thanks to flight safety improvement. However, flight safety performance indicators are still low. This is because the ensuring flight safety is largely due to the peculiarities of the impact of socio-cultural factors in different regions. The article is noted that flights are performed by humans with the help of technical means, but it is important to establish anthropological and socio-cultural factors that influence human decision-making. But during the process of communication between the representatives of technocratic and traditionalist societies, misunderstandings, differences of interpretations keep arising. These differences in interpretations are the result of sociocultural differences. In a traditionalist society; the priority of the senior in status has an unconditional priority over the impersonal universalism of the instructions and norms. From the standpoint of technocratic thinking, the requirements of mechanisms, technical systems and norms have unconditional priority over human orders. But from the standpoint of the traditionalist world view the system of interpersonal relations the dominant are the attitudes and demands of the person, senior in status. Independent, analytical thinking can free a person from the unconditional recognition of the authority of the senior in status.
\end{abstract}

\section{Introduction}

Globalization involves the intensive development of transport industries. Accordingly, transport, especially by air, should not only be convenient and accessible, but, above all, safe. A large number of international norms and standards designed to ensure the safety of air services do not always meet this goal. This raises the question of the reasons for the ineffectiveness of international aviation rules and regulations. Identifying these causes and finding ways to overcome them is an urgent requirement for different branches of knowledge, both technical and humanitarian.

Based on the fact that flights are performed by humans with the help of technical means, it is important to establish anthropological and socio-cultural factors that influence human decision-making, especially in critical situations. The results of the study can be used in the development of operating procedures, standards and norms that ensure flight safety. In this regard, it should be emphasized that international organizations that develop regulations

\footnotetext{
*Corresponding author: podatetiana@ukr.net
} 
must take into account the fact that people, with their capabilities and limitations, solve problems from different socio-cultural perspectives. As long as the presence of sociocultural differences is not taken into account in the development of working procedures, there is a danger of violating the flight rules and procedures.

\section{Materials and methods}

The key methodological principles of this study are comparative and socio-cultural methodological approaches in their dialectical unity. The application of the socio-cultural approach makes it possible to explore the specific conditions in which the decision-making process takes place, in the integrated dimension of human existence, in the context of man in his relationship with society, the nature of culture and type of sociality. The comparative approach allows, by comparing the socio-cultural dimensions of human existence in societies of different types, to identify key components that influence the decision-making process, especially in critical conditions.

\section{Result}

The unification of the rules of economic life and the establishment of an extensive system of international regulation of world economic relations and ties serve as the signs of the modern globalized world. As Ukrainian scientists point out: "Globalization processes are currently penetrating all spheres of social life worldwide, above all, through steady and inevitable advance of information and communication technology" [1]. Against the background of growing interdependence between different countries and the internationalization of economic life, there is a need for active and comprehensive regulation of the world economy, in particular in the aviation industry, which often involves cross-border operations.

The national economies of different countries are increasingly included in the global economic space with a universal system of regulation. The institutional regulator in the field of aviation is the specialized agency of the United Nations (the International Civil Aviation Organization (ICAO), which was established in accordance with the 1944 Chicago Convention on Civil Aviation. ICAO's mission is to organize and coordinate international cooperation in all aspects of civil aviation, as well as to ensure the safe, orderly development of international civil aviation worldwide and other aspects of the organization and coordination of international cooperation in all civil aviation matters, including international transport.

ICAO sets international standards for civil aviation and coordinates its development to increase safety and efficiency, seeking to "to help States to achieve the highest possible degree of uniformity in civil aviation regulations, standards, procedures, and organization" [2]. This means that ICAO standards have a supranational status, but at the same time, their implementation, unlike the norms of national legislation, is not subject to direct sanctions. As Paul Stephen Dempsey points out, "Outside the powers held by the UN Security Council to bring sanctions against States that violate international law, no UN body has unrestricted power to punish an errant State. Global governance instead works in a system of compliance, and softer levels of enforcement... Violations of its decision may result in a State's airlines denied authority to cross through the airspace of contracting States, and may result in suspension of the State's voting power in the Council and Assembly" [3]. Thus, despite the possibility of using instruments of influence in the form of a "softer level of security", the implementation of ICAO standards and requirements by individual entities may be questioned. This may be due to the accepted culture of safety in the form of a set of 
standards of behavior and thinking, which are generally shared in the organization to manage the main risks associated with direct activities, as well as accepted socio-cultural practices and mental attitudes.

It should be noted that among the theorists of globalization there are many supporters of the idea that the cultural factor is an important component of global development. In particular, such well-known scientists as P. Berger, R. Robertson, W. Beck, J. Tomlinson and others point out that without taking into account socio-cultural and axiological factors, further promotion of the integrative project of globalization becomes impossible.

In particular, J. Tomlinson believes that cultural globalization is responsible for the transmission of ideas, meanings and values, as well as for the development of social relations across world space [4]. Instead, R. Roberstson approaches globalization as a process of glocalization and unification of culture, which, in his opinion, leads the world not to unity, but to the creation of a situation of uncertainty [5]. In his works, the scientist points out that globalization acts primarily as a socio-cultural process, as a result of which there is such a global human condition, which can be defined in terms of "homogenization" and "heterogenization". If in the case of homogenization we are talking about global world structures created in the course of integrative processes, the term "heterogenization" refers to the specifics of the interaction of local cultures in a globalized world, which globalization seems to pull together. To denote this phenomenon, R Roberstson introduces the concept of "glocalization", which, in his opinion, reflects the simultaneous interaction of global and local levels in the overall process of globalization.

Developing the ideas of R. Roberstson, A. Malinowski draws an important conclusion for our study that "modern cultural space is a space of glocalization processes, which can be more precisely explicated as a glocal culture. Glocal culture is a world cultural space in which the local cultures interact and converge as cultural and historical entities that have their own mentality and are able to preserve their identity in the context of globalization" [6]. In particular, this means that, though the global attitudes and principles are of suprauniversal nature, they still co-exist with local cultural and historical formations and mental identities that significantly influence the decision-making process and can lead to uncertainty. In addition, there is a so-called behavioral world of the organization, in the form of qualities, feelings, values and relationships that have developed, which determine the models of interaction between people in the organization in such a way as to influence their way of thinking and acting. This aspect of culture is mostly concerned with the unwritten rules that govern the behavior and decisions of a group of people.

The events surrounding the large-scale aircraft crash provide a vivid example of the above-mentioned situation. The Russian plane, a Tupolev Tu-154M operated by Bashkirian Airlines, and the Boeing 757-200PF, operated by the German DHL courier network, crashed into each other over Lake Constance(the Boden See). As a result of the accident, 71 people, including 52 children, were killed on their way from Russia to Spain.

The commission set up by the German Federal Bureau of Aircraft Accidents Investigation (BFU) concluded that a number of technical factors, including the human factor, led to the crash, in particular the error of the Swiss air traffic controller. According to its report, published on May 1, 2004, the air traffic controller, wishing to prevent a collision between aircraft, instructed the crew of the Tu-154 to lower, which led to the crash [7]. The problem was that the air traffic controller noticed the dangerous approach of two planes too late. At the same time, a catastrophe could have been avoided if the crews of the two aircraft had been guided in the same way by international safety standards.

ICAO International Civil Aviation Organization regulations require that all international airline aircraft be equipped with an on-board TCAS collision warning system. This system monitors dangerous approaches between aircraft and instructs crews to change course to 
prevent a collision. To ensure flight safety, crews only need to strictly follow the TCAS instructions [8] (see fig. 1).

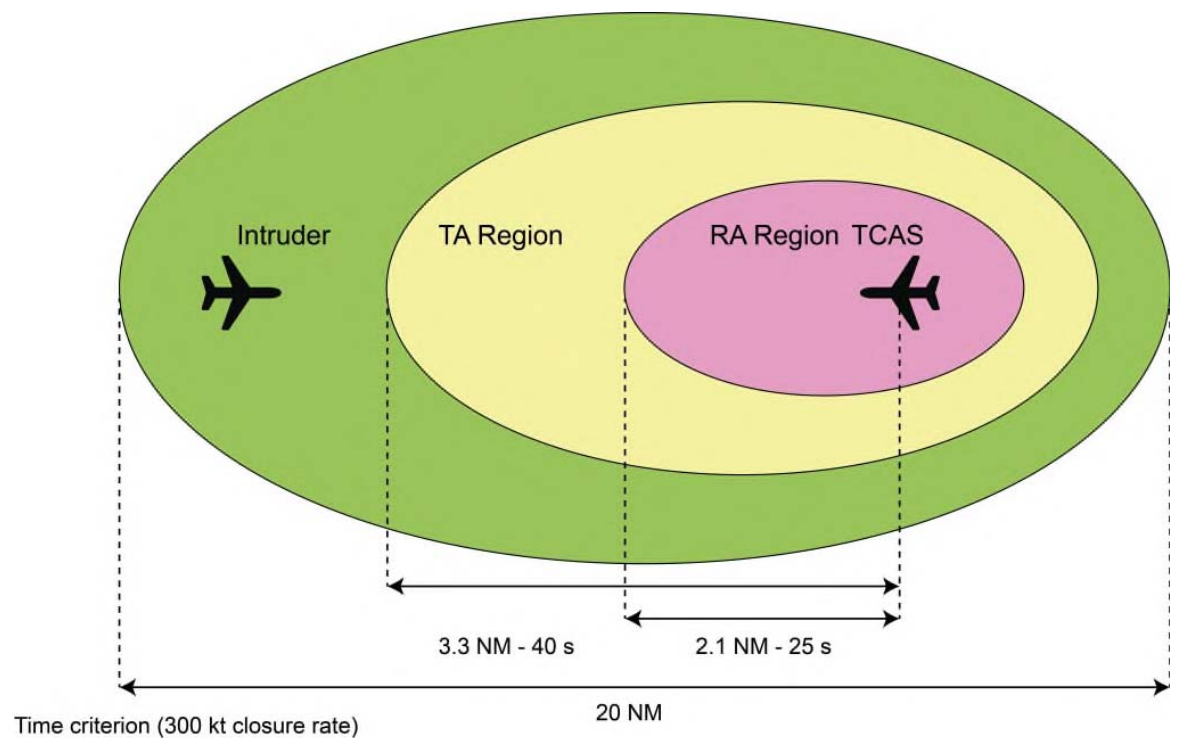

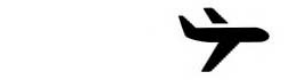

Altitude criterion

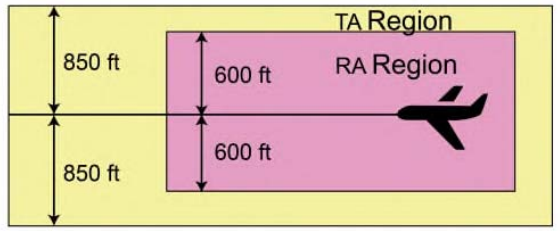

Example of ACAS Protection Volume between 5000 and 10000 feet

Fig. 1. Traffic collision avoidance system.

Therefore, in accordance with ICAO international requirements, the instructions of airborne collision avoidance systems take precedence over other instructions, including those of air traffic controllers.

The situation that primarily led to the crash of two aircraft was that the crew of the Boeing 757, in accordance with international standards and ICAO requirements, followed the instructions of the on board collision avoidance system, and dropped to the specified TCAS altitude, and the crew of Tu-154, contrary to TCAS instructions, gained altitude, followed the erroneous instructions of the air traffic controller, and also lowered the altitude. Although, according to the ICAO requirement, in the event of a TCAS system operation, the flight crew would have to ignore the air traffic controller's instructions and gain the altitude specified by the TCAS system, thus avoiding a collision.

This investigation has revealed an important socio-cultural component that also seems to affect international flight safety: in traditional societies, domestic traditions and rules take precedence over the universality of international norms, which are often ignored in the event of mutual contradictions. An indisputable requirement for Tu-154 pilots was the erroneous instruction of the air traffic controller, which on a mental level was given a priori priority by the crew over the "indifference" of ICAO abstract norms and impersonal requirements to change the course of the automatic TCAS system. It should be noted that 
this is fully consistent with the traditionalist worldview and system of relations, in which interpersonal and hierarchical status relations are dominant.

ICAO requirements, like many other international norms, are impersonal, i.e. their executors are the average people who a priori recognize the Western system of values and attitudes. This does not take into account the existing socio-cultural features that have developed in other regions of the globalized world. On the one hand, it is fair that ICAO requirements are drafted in an orderly manner, as international norms and standards, especially in the technical field, must be as universal, accurate and unambiguous as possible. They act as a guide for the specialist who performs certain outlined actions, i.e. have a procedural nature. On the other hand, for the non-Western tradition, this nature of interaction can rightly acquire signs of expansion of the Western system of relations and values. This is due to the fact that the modern culture of Postmodernism, with its inherent deconstructivism, weakens the apodictic nature of judgment and at the same time puts forward a new - procedural - framework for the unification of concepts. As a result, rational decisions, which have acquired the significance of norms, no longer represent an essential axiological and substantive form, but rather a procedural nature, becoming a tool for managing socio-political and economic processes using transnational relations and supranational institutions, through which cultural assimilation takes place at the procedural level.

In such conditions, a rational decision, which has acquired the significance of the norm and emerged through the establishment of a communicative consensus, has not an essential, unchanging, essentialist, substantive form, but rather a procedural nature. These tendencies were pointed out by Ju Habermas in the work "The rationalization of law and diagnosis of the times", arguing that at the stage of modern law, norms can be considered as arbitrary establishments and evaluated according to them only hypothetically, according to current principles [9]. Thus, in the postmodern culture the criterion for the rationality of norms is "not the universality of the form inherent in law, but the universality of provisions that are reinterpreted in terms of discursive ethics. Such provisions arise and find their confirmation in the "intersubjectivity of the practice of argumentation", which is procedural in its nature of the existence of open discourse" [10]. The above indicates that the legitimation of accepted norms and rules in the postmodern era occurs only through the regulation of discourse. Under such conditions, integration takes the form of expansion and occurs only along the prescriptive line of normative-procedural formations, designed to optimize certain actions through certain rules and procedures.

Thus, within the framework of the Global Governance system, international norms and rules are formed as if the whole world is already a homogeneous socio-cultural environment. This testifies to the technocracy in views on the essence of global governance that prevails in international politics and relations. The instrumentalist approach in global relations, conditioned by it, eliminates the axiological and socio-cultural components. Such a tendency - to remain contextually within the organizational requirements and guidelines, while leveling the value-content and socio-cultural component - can be traced in many international conventions and agreements. International conventions and norms seem to be instruments for managing social and political processes through transnational relations and supra-State institutions, due to which the Western way of life is implemented at the procedural level, rather than by elements of socio-cultural dialogue and communication.

This shows the technocratic approach inherent in Western civilization. "In other words, when technology rises to the rank of the absolute, then everything else, and above all man, must be equal to this absolute, to be built on its image and likeness", states O. Arkhypov and O. Okhrymenko [11]. In the context of technocratic civilization, this approach has to a certain extent proved itself by ensuring that human technology is clearly applied when the actor becomes part of, rather than the organizer of, the technical process. These norms and 
requirements worked well when they operated exclusively within countries of a similar spirit, with an identical sociocultural nature. That is, in the countries united by the concept of "Western civilization". It was them who first embarked on the path of technocratic development, became the basis of industrial and later post-industrial society. "Modern manmade civilization is a socio-cultural space that has fully undergone the creative and transformative influence of man. Technology has reached such a scale of spread and such an effect on human life that we can talk about a special shell of the globe, saturated with technical devices - the technosphere. The growth in the number and variety of technology has led to a change in style, rhythms and content of human life [12]. When other countries, with their different sociocultural backgrounds, began to be incorporated into the orbit of a technocratic civilization, these norms weakened. The given example with a plane crash is bright, but, unfortunately, not singular. It argues that, for representatives of societies with different levels of socio-cultural development, the universality of international technical norms is not an absolute indication of the necessity of their implementation.

\section{Discussion}

In order to find out what is the difference between the approaches of representatives of different types of societies, especially in in critical conditions, it is necessary to dwell on the concept of "traditionalist society". Traditionalist society is a well-established term in the social sciences that describes a society of a certain type. We will not delve into all its aspects, instead, we will just point out that structure, hierarchy and status are inherent for this type of family and social sphere. Moreover, according to some researchers, in modern conditions "traditional institutions provide a platform for local communities to respond to and adapt themselves to the changing times and conditions" [13].

In such lower-status societies, the orders and instructions of the senior in status must be obeyed unconditionally. The person with the highest status is the legitimate interpreter of existing norms and is responsible for the results of actions taken at his request. The authority of the senior in status person is reinforced by tradition in all spheres of public life. Therefore, the integral component of socialization in the traditionalist society is orientation on the senior in status person. Tradition is the basis for the legitimization of relationships, and presupposes the unquestioned authority of the superior. In a globalized world, there are many countries with transitional economies that still have more or less numerous components of traditional society. Although these societies are adapting to the characteristics of the modern world, they continue to maintain their basic components. If these components are sufficiently numerous in a society, it is defined as a traditionalist society. In this article, using the term "traditionalist society", we mean a society in which the authority of people with a senior status is preserved and their priority is recognized, especially in emergency. Therefore, it is in emergencies, in the interaction of representatives of technocratic and traditionalist societies, that misunderstandings, differences of interpretations, etc. keep arising. These differences in interpretations, understandings and actions are, in fact, the result of socio-cultural differences, as demonstrated by the catastrophe over Lake Constance.

Given that in a traditionalist society, the priority of the senior in status has an unconditional priority over the impersonal universalism of the instructions and norms, the indisputable requirement for the pilots of TU-154 was the requirement of the air traffic controller, senior in status to the pilot. His authority in the minds of the crew outweighed the credibility of the on-board TCAS system and the impersonal ICAO requirements. From the standpoint of technocratic thinking, the requirements of mechanisms, technical systems and norms have unconditional priority over human orders. In technocratic civilization, a priori recognition is given to the superiority of technology over man. But from the 
standpoint of the traditionalist world view and the system of interpersonal relations the dominant are the attitudes and demands of the person, especially the one senior in status. The unalterable demand to submit to the authority of a person superior in status, instead of the impersonal requirements of the technical system and instructions, seems to them completely natural and justified. After all, in traditionalist societies, it is considered unacceptable not to comply with a requirement or order of a senior in status. He acts as a mediator between the technical devices that can go wrong and the direct executor of the action, taking on the entire burden of responsibility. This is typical of societies where hierarchical human-to-human relations take precedence over machine-to-human, which is customary in a technocratic society. The priority of personal guidance over impersonal requirements of norms, technical devices, systems, etc., is understood as normative. After all, tradition takes precedence over universal norms. Therefore, when there is a conflict between the requirements of a senior in status specialist and the guidelines of technical systems, instructions and norms, the representatives of a traditionalist society are likely to meet the requirements of the human being, because this corresponds to their worldview, mentality and so forth.

Each system strives for self-preservation. Therefore, in the modern world non-Western societies are acting as recipients of the technocratic culture of Western civilization, at the same time striving to preserve the identity and autonomy of their own socio-cultural space. This is primarily due to the social practices, which were established in their social space during the common historical life. According to E Giddens, social practices, which are constantly reproduced by the social actors in the process of social existence, have "structural properties", and their structure, as a model of social relations, manifests itself in the form of such practices, and records the behavior of competent actors in the same way as the memory does [14]. Therefore, social actions cannot be artificially created by social actors at their own discretion. They cannot be established "from above", as is the case with international norms, either. After all, their implementation will be directly dependent on whether these norms are related to the structural properties of social relations of each particular society and its routine social practices that have developed in it historically. At the same time, it is also necessary to take into account the psychological motivation of the actor, within which specific behavioral scenarios unfold. Social action is only reproduced by actors in every society in the same way that people act in it as actors. In addition, in the course of their own activities, and through it, social figures reproduce the very conditions that make this activity the only possible one, while legitimizing it in the system of relations. It is on these grounds that, in the course of social practice, the behavior of individual actors reproduces the structural features of the social system. If a technocratic society de facto recognizes the priority of technology over man, turning it into an appendage of technical systems, then traditionalist societies retain and recognize the priority of human community, maintaining more or less hierarchical social and interpersonal relations.

The given example points to another problem. The pilots, like all air traffic participants, must be aware of the priority of ICAO requirements as sound, evidence-based guidelines. When the observance of these norms is based solely on status authority, it will be only a substitution of the priority of senior status characteristic of traditionalist societies, without changing the essence of the phenomenon. The technocratic civilization recognizes the unconditional authority of technological norms, rules and indicators of technical systems. The authority of the senior in status personis in fact replaced in a technocratic society by the unconditional authority of the impersonal norms set by depersonalized organizations and technological standards. Procedures should therefore be designed in such a way as to avoid to the fullest degree the possibility that human attitudes and norms may be at odds with each other. 
With the growing complexity of processes in aviation and increased air traffic, it is necessary to take into account the human factor, which always includes a socio-cultural component. Undoubtedly, the speed of human reaction is inferior to the capabilities of technical devices. But a person is able to think outside the box, to find adequate situations and solutions more effectively than a machine. This is due to the fact that a person works with a wider range of data and, which is more importantly, such inter-human relationships include not only purely rational aspects that can lead to a binary system, which could be "understood" by the machine, but also various spheres of the collective unconscious, which people take into account when making decisions, while machines can't do it. In addition, technical devices are able to work only "with a logical sequential organization and processing of data, but not with random associations. Typically, a computer holds information in well-structured hierarchies and matrices, while the human mind has a special ability to establish connections between random pieces of that data" [15]. It should be also borne in mind that technical devices belong to the man-made human world of "second nature" - a category much wider in scope than all the equipment and technology combined. Thus, a man never serves as an appendage of technology. Consequently, in the process of training pilots, special attention should be paid not only to the acquisition of purely technical skills and knowledge, but also to the formation of their independent thinking, rationality and analytical skills. Pilots must not just blindly follow existing requirements and guidelines, but at the same time clearly understand their meaning. International rules in aviation, ways of technical systems functioning, are based on the objective laws fixed in system of laws of exact sciences. They rely on the objective laws of natural and technical systems functioning, and therefore are rational and binding.

ICAO norms are objective in nature, extrapolating the objective laws of the exact sciences on which aviation is based to the specific actions of participants in the aviation process. They are normative and unconditional to comply with due to their rationality and scientificity, but not due to the authority of the organization that approved them. Only independent, analytical thinking can free a person from the unconditional recognition of the authority of the senior in status, regardless of whether it is a person or a machine that provides rationality and awareness of its actions. Human-dimensional and, at the same time, rational philosophy is called upon to form the independent, analytical thinking necessary for the operation of modern technology. "Modern style of socio-cultural regulation, which provides for the presence of various forms of knowledge, stimulates a person's independent choice of a strategy of action in everyday and professional activities" [12]. Only an educated, versatile and independently-minded person is able to act optimally in unpredictable critical circumstances, relying on established norms, system indicators and to consciously choose the optimal course of action. Improving the quality of aviation education is a requirement of the time, a condition for sustainable development of the aviation industry, air safety.

\section{Conclusions}

The research suggests that, in a globalizing world, in the process of unifying the rules of economic life and establishing the extensive system of transnational regulation of international economic ties and relationships in the aviation industry, ICAO in particular, we should take into account the socio-cultural factor that affects flight safety. This is because alongside the supra-universal nature of global precepts and principles, there are local cultural and historical entities and mental identities, which have a significant effect on the decision-making process and can bring the system into a state of uncertainty. In particular, in traditionalist societies, domestic traditions and rules take precedence over the universalism of international norms, which are often ignored when mutual contradictions 
arise. Procedures should therefore be designed in such a way as to avoid, to the extent possible, the possibility that human attitudes and the provisions of legal instruments may be at odds with each other. Complications of international aviation rules and regulations require the upgrading of the professional level of specialists capable of optimally solving non-standard problems. In the process of training pilots, therefore, special attention should be paid not only to the mechanical assimilation of purely technical skills and knowledge, but also to the study of philosophy. The development of philosophical analytical thinking skills among pilots is not only a call of the times, but also an important condition for flight safety. The inclusion of socio-cultural factors and the improvement of the quality of aviation education are also important in addressing current problems in the field of aviation safety.

\section{References}

1 A. Gudmanian, L. Drotianko, S. Sydorenko, O. Zhuravliova, S. Yahodzinskyi, E3S Web Conf. 135, 03081 (2019) https://doi.org/10.1051/e3sconf/201913503081

2 The History of ICAO and the Chicago Convention Site ICAO https://www.icao.int/about-icao/History/Pages/default.aspx

3 P.S. Dempsey, German Journal of Air \& Space Law, 229 (2015) https://ssrn.com/abstract=2786731 http://dx.doi.org/10.2139/ssrn.2786731

4 J. Tomlinson, Globalization and Culture (University of Chicago Press, 1999)

5 R. Robertson, Globalization: Social Theory and Global Culture (SAGE PublicationsLtd, 1992)

6 A. Malinovskiy, Bulletin of the Tomsk State Pedagogical University 1(129), 176-179 (2013)

7 Investigation Report AX 001-1-2/022002 Involving Boeing B757-200 and Tupolev TU 154 M (BFU: German Federal Bureau of Aircraft Accidents Investigation) Near Ueber lingen Lake of Constance Germany https://www.bfuweb.de/EN/Publications/Investigation\%20Report/2002/Report_02_AX001-1-

2_Ueberlingen_Report.pdf?_blob=publicationFile

8 Traffic collision avoidance system Retrieved from https://ru.qwe.wiki/wiki/Traffic_collision_avoidance_system

9 Ju. Khabermas, Sociological Review 10(3), 131-154 (2011)

10 E. A. Chichneva, Moscow University Bulletin 2, 85-110 (2001)

11 O. P. Arkhypov, O. H. Okhrymenko, Philosophical Problems of Modern Science 76, 29-37 (1991)

12 G. V. Panina, Socio-cultural expertise as a factor in the development of technogenic civilization, Site SP KurdiumovaSynergetics [http://spkudyumov.ru/misc/panina] (2007)

13 A. Dutta, Humanities \& Social Sciences Reviews 8 (3), 392-399 (2020) https://doi.org/10.18510/hssr.2020.8342

14 E. Giddens, Organization of society: an outline of the theory of structuralization, 528 (Academic Project, Moscow, 2003)

15 T. Berners-Li, M. Fichetti, Web Foundation: where the World Wide Web began and wil lcome from, 207 (Kyiv-Mohyla Academy, Kyiv, 2007) 